\title{
Cellular Response of the Tendon Sheath in Tendon Injury: Experimental Research in New Zealand Rabbits
}

Nick Sekouris ${ }^{1 *}$, Athanasios Kefalas ${ }^{2}$, Konstantinos Soultanis ${ }^{3}$, Kalliopi Diamantopoulou ${ }^{4}$, Georgia Karagiannopoulou ${ }^{5}$, Panayotis Soucacos ${ }^{3}$ and Aristides Zoubos ${ }^{3}$

'Metropolitan' General Hospital, Athens, Greece

${ }^{2}$ Hospital of loannina, Greece

'University of Athens, Medical School, 'ATTIKON' University Hospital, Haidari, Athens, Greece

${ }^{4}$ Department of Pathology, 'RED CROSS' General Hospital, Athens, Greece

${ }^{5}$ Department of Pathology, Medical School, 'ARISTOTELIO' University Hospital, U.T.H., Thessaloniki, Greece

\begin{abstract}
Purpose: We aimed to investigate the synovial sheath cell migration in response to flexor tendon injury under direct visualization.

Methods: We used New Zealand rabbits based on an animal model described in previous studies, which we modified in order to create conditions similar to real tendon injury and healing. We used a special paint marker (1,1'-dioctadecyl1-3,3,3',3'-tetramethylindocarbocyanine-percolate-Dil) of the sheath cells. The Flexor Digitorum Profondus first was sectioned through a distal skin incision and pulled outside the sheath through a proximal skin incision. Then the sheath was labeled. A second intrasynovial full thickness cross-section of the flexor was done and repaired by Kessler and running type suture. We harvested the tendons day 1, 3, 5, 7, 14 and 28 after tendon injury. Tendon sections were prepared with cryotomy and tested by infrared microscope. To evaluate our results, we divided the migration of synovial sheath cells in four phases: $1^{\text {st }}$ phase) no or sporadic migration to the surface of the tendon, $2^{\text {nd }}$ phase) massive migration to the surface of the tendon, $3^{\text {rd }}$ phase) migration just below the surface of the tendon, and $4^{\text {th }}$ phase) migration in the endotenon. For each day's group the percentage of tendon sections in each phase of migration was determined.
\end{abstract}

Results: According to our findings the second phase of migration of cells was $85 \%$ reached on the $3^{\text {rd }}$ day, the third phase $66.6 \%$ reached on the seventh day and the fourth phase $50 \%$ reached on the fourteenth day after flexor tendon injury.

Conclusions: This study confirms that the synovial sheath cells migrate first into the surface and later into the core of the healing tendon.

keywords: Synovial sheath cells; Neutrophils; Tendon injury

\section{Introduction}

The tendons are units of musculoskeletal tissue that transmit force from muscle to bone. The normal tendon consists of soft and fibrous connective tissue that is composed of densely packed collagen fiber bundles aligned parallel to the longitudinal tendon axis and surrounded by tendon sheath, also consisting of extracellular matrix components. Collagen constitutes $75 \%$ of the dry tendon weight and its main function is to withstand and transmit large forces between muscle and bone.

In most cases of tendon laceration or rupture, surgical intervention is required to direct the natural process of healing. Tendon repair is a slow process that takes place in three overlapping stages. The initial stage of repair involves the inflammatory phase. Erythrocytes and inflammatory cells, especially neutrophils, enter the area of the lesion. In the first twenty-four hours, monocytes and macrophages arrive and a phagocytosis process of the necrotic material is taking place. Angiogenic factors are released during this phase and initiate the formation of a vascular network [1]. Tenocytes migrate to the damaged area and synthesize collagen type III [2]. The second stage called proliferative phase involves the continued recruitment of fibroblasts and their rapid proliferation at the wound site which are responsible for the synthesis of collagens, proteoglycans and other components of the extracellular matrix. At this point the extracellular matrix is largely composed of type III collagen [2]. At the end of the proliferative stage, the repair tissue is highly cellular and contains relatively large amounts of water and an abundance of extracellular matrix components. The third stage called remodeling stage begins 6-8 weeks after injury and is characterized by a decrease in cellular, matrix and type III collagen synthesis and an increase in type I collagen synthesis. The remodeling phase can be divided into a consolidation and a maturation stage [3]. The consolidation stage starts from the sixth week and lasts until the tenth week. During this period, the repair tissue changes from cellular to fibrous. Cellular metabolism remains high at this stage. Tenocytes and collagen fibers are aligned with the direction of the stress forces [4]. More collagen type I is produced during this phase [5]. After the tenth week the maturation stage starts. At this stage the fibrous tissue is gradually replaced with scar-like tendon tissue [6]. This process takes

*Corresponding author: Nick Sekouris, Consultant Orthopeadic, 'Metropolitan' General Hospital, Margaritas 25, Elliniko, 16777, Athens, Greece, Tel: 0030 6985010730; E-mail: nick_sekouris@yahoo.com

Received September 17, 2013; Accepted October 17, 2013; Published October 21, 2013

Citation: Sekouris N, Kefalas A, Soultanis K, Diamantopoulou K, Karagiannopoulou G, et al. (2013) Cellular Response of the Tendon Sheath in Tendon Injury: Experimental Research in New Zealand Rabbits. J Trauma Treat S4: 004. doi:10.4172/2167-1222.S4-004

Copyright: (c) 2013 Sekouris N, et al. This is an open-access article distributed under the terms of the Creative Commons Attribution License, which permits unrestricted use, distribution, and reproduction in any medium, provided the original author and source are credited. 
Citation: Sekouris N, Kefalas A, Soultanis K, Diamantopoulou K, Karagiannopoulou G, et al. (2013) Cellular Response of the Tendon Sheath in Tendon Injury: Experimental Research in New Zealand Rabbits. J Trauma Treat S4: 004. doi:10.4172/2167-1222.S4-004

about a year, during which the cellular metabolism gradually decreases [7].

Two distinct models have been proposed to explain the mechanism of tendon healing [8-10]. Intrinsic healing entails the proliferation and migration of cells from epitenon into the injury site [11,12]. During extrinsic healing fibroblasts and inflammatory cells invade the healing site from the periphery or external tissue in order to initiate and later promote repair and regeneration. This process involves the initial formation of adhesions. Intrinsic healing gives better biomechanical results, unlike the extrinsic healing in which the scar tissue adhesions between the tendon and the sheath can cause fixed contracture [13]. In most cases both mechanisms are involved in the healing process that is dependent on several factors including tendon location, extent of trauma and postoperative motion.

The healing of injured is achieved mainly by the epitenon cells [14]. Endotenon cells contribute to the healing process by producing larger and more mature collagen fibers [15]. Different types of collagen produced by different cell types are involved in the healing of the tendon at different phases. Collagen is initially synthesized by epitenon and later by endotenon cells [16-19]. The involvement of each cell type in collagen synthesis can be affected by the type of wound, the anatomical location of the lesion, the existence of synovial tendon sheaths, and the stress developed by the movement of the repaired tendon [20].

During tendon repair several biological factors such as Metallo Proteinases (MMPs) [21], growth factors and cytokines [22,23] are involved in the activation and regulation of the cellular response. These factors bind to specific receptors that are present on the cellular surface and activate specific signaling events within the cell. The release of these factors is stimulated by cells that are located at the site of injury [24]. Other substances that can affect the healing process are nitric acid [25], the substance P and the Calcitonin Gene-Related Peptide (CGRP) $[26,27]$.

Numerous studies of tendon healing have been performed either on transected tendons of animal models or ruptured human tendons in cadavers. However, the conditions under which healing and cellular response of both the cells of the injured tendon and the cells of neighboring tissues take place, have not been fully elucidated.

\section{Purpose}

The aim of this study was to investigate the synovial sheath cell

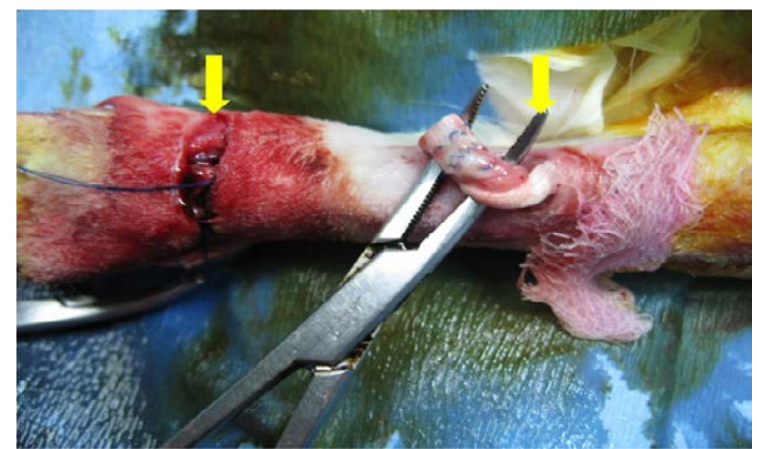

Figure 1: The arrows show the two skin incisions (distal on the left and proximal on the right). The proximal part of the flexor is sutured, and the tendon is going to place into the synovial sheath for the distal suturing. The synovial sheath for the distal suturing. The synovial sheath is already labeled with Dil dye. migration in response to flexor tendon injury by selective cell labeling and direct observation. Previous studies have investigated the fibroblast migration from the synovial sheath to the injury site, using animal models. The tendon was injured by a longitudinal incision causing partial tendon tear, after having previously marked the sheath cells with a special dye [28]. We adopted a similar methodology, but we performed complete tendon intersection and sutured the tendon trying to reproduce realistic conditions of tendon healing.

\section{Material and Methods}

Thirty six New Zealand rabbits were used for this study with the approval of the ethics committee. General anesthesia was induced by intramuscular injection of fentanyl-fluanisone (Hypnorm, Jensen Pharmaceutical Ltd.). Then the rabbit was prepared by shaving its front limbs and washing it thoroughly with a solution of povidone iodine 10\% (Betadine, Lavipharm Hellas AE). Then local anesthetic (lidocaine hydrochloride 2\%) was injected in the areas of skin incision. Two small transverse skin incisions of 1-1.5 $\mathrm{cm}$ were performed, one above the ankle (proximal incision) and the other below the ankle of the front leg (distal incision). Through the distal skin incision the Flexor Digitorum Superficialis (FDS) was moved to the side in order to approach the Flexor Digitorum Profondus (FDP). The FDP was transected at two different levels, the first, at the level of the distal skin incision and the second at the level of the proximal skin incision. After the first transection (at the level of the distal skin incision) the FDP was dragged outside its sheath from the proximal skin incision and protected inside gauze soaked with saline. A gauze impregnated with a special dye, 1,1 '-dioctadecyl1-3, 3,3', 3'-tet-ramethylindocarbocyanine percolate (Dil) (Molecular Probes Inc., Eugene, OR) was introduced in the empty tendon-sheath and left there for 5 minutes. This is a fluorescent lipophilic membrane tracer dye. Previous studies have shown that a 5 minutes period allows for a good uptake of the Dil ${ }^{\mathrm{xx}}$. After removing the gauze a diligent washing of the sheath with saline $0.9 \%$ was done. The washing was repeated at least 5 times with $5 \mathrm{ml}$ saline boluses to ensure no diffusion of the dye in other tissues. Then a second cross-section at the middle of the intrasynovial part of the FDP was performed. The tendon was repaired using a Kessler's type suture with nylon $4 / 0$ and running suturing with prolene 6/0. The FDP was dragged back into the sheath and the distal incision was repaired at the same way. Eventually, the wound was closed with nylon $3 / 0$ (Figure 1). The exact same procedure was performed at the opposite side, but without intersection of the intrasynovial part of the FDP (i.e. without the proximal tendon incision). This side served as a control. This process was done in all rabbits and then they were freed without any type of cast-immobilization of the limbs.

The animals were divided into 6 groups ( 6 animals for each group) in order to study the histologic samples of the flexors in $1,3,5,7,14$ and 28 days after the initial procedure. The rabbits were killed with an overdose of fentanyl-fluanisone (Hypnodorm, Jansen) administered intramuscularly. In each group the FDP was removed and snap-frozen within a cry-vial in liquid nitrogen and stored at $-80^{\circ} \mathrm{C}$. The FDPs were then sectioned at $8 \mu \mathrm{m}$ thickness using a cryostat with a tungsten blade with 4 representative sections cut from each tendon. Four sections were assessed from each flexor, with 6 animals being assessed for each time period, hence a total of 144 sections were analyzed in this study. The sections obtained were visualized under light and ultraviolet microscopy. Fluorescent Dil-dyed cells were visualized under ultraviolet light with a terta methyl rhodamine iso thiocyanate filter The images of the sections were taken using a digital camera connected to a computer and saved as a JPGS files. To evaluate the results, we divided the migration of cells in four phases: $1^{\text {st }}$ phase) no or sporadic 
Citation: Sekouris N, Kefalas A, Soultanis K, Diamantopoulou K, Karagiannopoulou G, et al. (2013) Cellular Response of the Tendon Sheath in Tendon Injury: Experimental Research in New Zealand Rabbits. J Trauma Treat S4: 004. doi:10.4172/2167-1222.S4-004
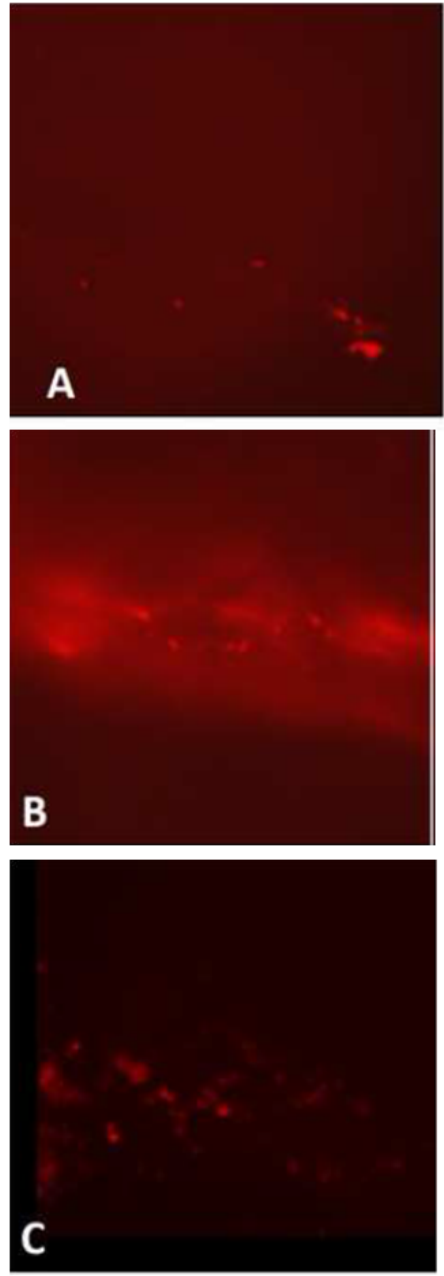

Figure 2: (A). Ultraviolet photomicrographs of longitudinal tendon frozen sections taken at sequential time intervals after the procedure. On the 3 ro day labeled cells are present upper the tendon surface. (B). Ultraviolet photomicrographs of longitudinal tendon frozen sections taken at sequential time intervals after the procedure. On the 7th day labeled cells are up and below the tendon surface. (C). Ultraviolet photomicrographs of longitudinal below the tendon surface. (C). Ultraviolet photomicrographs of longitudinal
tendon frozen sections taken at sequential time intervals after the procedure. On the 28th day labeled cells are in all tendon body

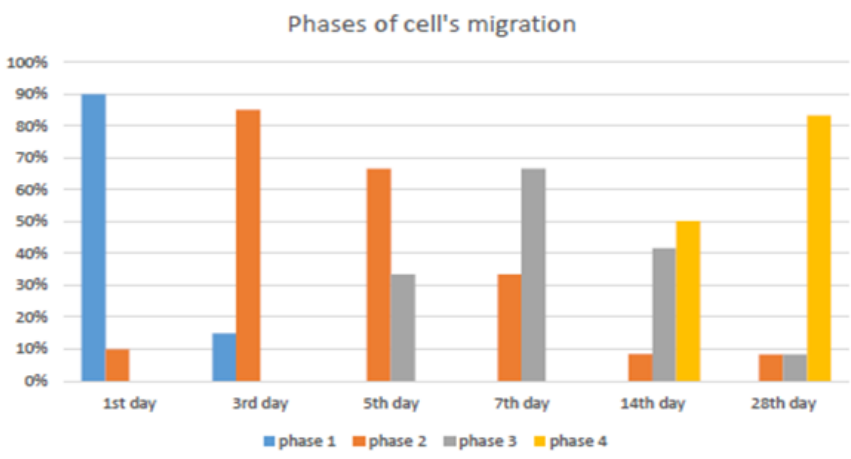

Chart 1: Percentage of tendon sections in each phase of migration for days $1,3,5,7,14$ and 28 after tendon intersection and repair. (Four phases of migration: $1^{\text {st }}$ phase: sporadic or no migration to the surface of the tendon, $2^{\text {nd }}$ phase: massive migration to the surface of the tendon, $3^{\text {rd }}$ phase: massive migration just below the surface of the tendon, and $4^{\text {th }}$ phase: massive migration in the core of the tendon). migration to the surface of the tendon, $2^{\text {nd }}$ phase) massive migration to the surface of the tendon, $3^{\text {rd }}$ phase) migration just below the surface of the tendon, and $4^{\text {th }}$ phase) migration in the endotenon. For each day group the percentage of tendon sections in each phase of migration was determined.

\section{Results}

We repeated the process in another 3 rabbits, in order to have the same number of rabbits in each group, because in two, the distal suturing failed and in one, autocanibalism due to infection of the wound was observed.

On the first day after tendon injury, in $90 \%$ of the sections the cells were in the first phase of migration and in $10 \%$ in the second phase of migration. On the third day post injury we observed a massive collection of fibrocytes on the surface of the tendon (85\% of sections were in the $2^{\text {nd }}$ phase and $15 \%$ were in the $1^{\text {st }}$ phase). On the fifth day post injury sporadic migrations just below the surface of the tendon was observed (66.6\% were in $2^{\text {nd }}$ phase and $33.4 \%$ in the $3^{\text {rd }}$ phase). On the seventh day post injury massive migration just beneath the surface of the tendon was observed $\left(66.6 \%\right.$ were in the $3^{\text {rd }}$ phase and $33.4 \%$ in the $2^{\text {nd }}$ phase). After the fourteenth day post injury a massive collection of fibroblasts in the endotenon was observed (Figure 2). On the fourteenth day post injury $50 \%$ were in the $4^{\text {th }}$ phase, $41.6 \%$ were in the $2^{\text {nd }}$ phase and $8.4 \%$ were in the $3^{\text {rd }}$ phase. On the twenty-eighth day post injury $83.4 \%$ were in the $4^{\text {th }}$ phase, $8.3 \%$ were in the $3^{\text {rd }}$ phase and $8.3 \%$ were in the $2^{\text {nd }}$ phase. According to the staging of migration of cells, the second phase was reached in the third day, the third phase in the seventh day and the fourth phase in the fourteenth day after the flexor tendon injury (Chart 1).

On the contralateral limbs, which were used as control, we noticed that on the first day after the flexor tendon injury $90 \%$ of sections were in the $1^{\text {st }}$ phase of migration and $10 \%$ in the $2^{\text {nd }}$ phase. On the third day $80 \%$ were in the $1^{\text {st }}$ phase and $20 \%$ were in the $2^{\text {nd }}$ phase. On the fifth day $50 \%$ were in the $1^{\text {st }}$ phase and a $50 \%$ were in the $2^{\text {nd }}$ phase and remained the same for the rest of the groups $\left(7^{\text {th }}, 14^{\text {th }}\right.$ and $28^{\text {th }}$ day group). On the control sections we did not observe any $3^{\text {rd }}$ or $4^{\text {th }}$ phase of migration (Table 1).

\section{Statistical Analysis}

Simple linear regression analysis was used to check the correlation between the number of days after the tendon injury and the phase of the

\begin{tabular}{|c|c|c|c|c|}
\hline \multicolumn{5}{|c|}{ INJURED TENDONS } \\
\hline & $\mathbf{1}^{\text {st }}$ phase & $\mathbf{2}^{\text {nd }}$ phase & $\mathbf{3}^{\text {rd }}$ phase & $\mathbf{4}^{\text {th }}$ phase \\
\hline $\mathbf{1}^{\text {st }}$ day & $90 \%$ & $10 \%$ & & \\
\hline $3^{\text {rd }}$ day & $15 \%$ & $85 \%$ & & \\
\hline $\mathbf{5}^{\text {th }}$ day & & $66.6 \%$ & $33.4 \%$ & \\
\hline $\mathbf{7}^{\text {th }}$ day & & $33.4 \%$ & $66.6 \%$ & \\
\hline $\mathbf{1 4}^{\text {th }}$ day & & $8.4 \%$ & $41.6 \%$ & $50 \%$ \\
\hline $\mathbf{2 8}^{\text {th }}$ day & & $8.3 \%$ & $8.3 \%$ & $83 \%$ \\
\hline \multicolumn{2}{|c|}{} & $\mathbf{C O N T R O L}$ & & \\
\hline $\mathbf{1}^{\text {st }}$ day & $90 \%$ & $10 \%$ & & \\
\hline $3^{\text {rd }}$ day & $80 \%$ & $20 \%$ & & \\
\hline $\mathbf{5}^{\text {th }}$ day & $50 \%$ & $50 \%$ & & \\
\hline $7^{\text {th }}$ day & $50 \%$ & $50 \%$ & & \\
\hline $\mathbf{1 4}^{\text {th }}$ day & $50 \%$ & $50 \%$ & & \\
\hline $\mathbf{2 8}^{\text {th }}$ day & $50 \%$ & $50 \%$ & & \\
\hline & & & \\
\hline
\end{tabular}

Table 1: Percentage of tendon sections for each day group in each phase of migration. 
Citation: Sekouris N, Kefalas A, Soultanis K, Diamantopoulou K, Karagiannopoulou G, et al. (2013) Cellular Response of the Tendon Sheath in Tendon Injury: Experimental Research in New Zealand Rabbits. J Trauma Treat S4: 004. doi:10.4172/2167-1222.S4-004

cells migration using the software of SPSS 16.0. Based on that analysis we estimated that the $r$ square equaled 0.568 and the b1 equaled 5.749 for $\mathrm{p}=0.00$. That means there is a weak but statistically significant correlation between the number of days after surgery and the phase of cell migration.

\section{Discussion}

The use of dye Dil to mark flexor fibroblasts has been described by McNeilly et al. [29], where the studied cell response to mechanical loading. This type of fluorescent membrane label has the most appropriate characteristics to study the cells migration: lack of leakage from cells, cellular specificity, and sufficient longevity. Once attached to cells the dye in not passed to other cells. This dye, later, was used by Jones et al. [30] to study the migration of fibroblasts from the epitenon and by Harrison et al. [28] who studied the migration of fibroblasts from the synovial sheath with an animal model of partial intersection of the flexor. We adopted the same methodology as the previous two studies to study the behavior of cells in the sheath during healing after complete intersection suturing of the flexor, i.e. as often happens in reality.

This study confirms that there is migration of cells from the synovial sheath in the core of the flexor tendon during the healing process. On the first day after the injury no significant migration is noted. On the third post-injury day a significant cell migration on the tendon surface was noted. In the first 3 days of the flexor injury, there is intense enzymatic activity in epitenon and after two weeks, there is intense enzymatic activity in endotenon [31]. This schedule coincides with that of the migration of fibroblasts from the synovial sheath. But we do not know if this intense enzymatic activity is of the migrated fibroblast or if the fibroblast just stimulates the cells of the endotendon. On the seventh day a massive collection of fibroblast under the tendon surface was observed. After the fourteenth postoperative day a big number of fluorescent cells diffused in the core of the tendon were noted. Khan et al. [32] found differences in composition and type of collagen derived from fibroblasts of the sheath and epitenon. The participation of the fibroblasts of the synovial sheath in healing process of the injured flexor is associated with adhesions [33]. Berglund et al. [34] observed significantly increase of the levels of collagen I mRNA in the tendon sheath at 12 and 24 days after injury in contrast with the unvaried levels in injured tendons compared with the uninjured tendons. The same authors observed differences of type III mRNA levels and growth factors between synovial sheath cells and tendon cells. What is the rule of the synovial sheath cells in the tendon healing? A previous study has revealed many differences between synovial sheath cells and tendon cells regarding the type of collagen they produce and their association with the formation of adhesions. In our model control we observed that despite there is no migration from the sheath to the core of the tendon in uninjured tendons there is a migration to the tendon surface. If that observation is not because of dye diffusion could mean that there is a turnover of the synovial sheath cells between sheath and tendon surface. Considering that early mobilization prevent the formation of adhesions a hypothesis can be done. The synovial sheath is very active cells and in case of injury they migrate and stimulate the tendon cells to repair faster the lesion and to permit an earlier mobilization preventing the formation of adhesions. But if mobilization does not happen this faster collagen production create adhesions. A comparative study of the healing time between intrasynovial and extra synovial tendon injury should be done. An interesting study of Oryan et al. [35] showed a very slow healing in an extra synovial injured tendon (superficial digital flexor tendon of the hind leg of rabbit).
The statistical analysis revealed that there is synovial sheath migration in the injured tendon but there is a weak correlation between the day after injury and the phase of cells migration. That weak correlation could be explained because of the variability of the migration's phases observed during the days after the tendon injury. Despite the majority of the cells were in the $4^{\text {th }}$ phase of migration at the fourteenth day after surgery (50\%) and at the twenty-eighth day $(83.4 \%)$ contemporaneously others phases of cell's migration observed.

It is important to understand the biology of healing of the injured tendon to find strategies that can stimulate healing and also prevents the formation of adhesions. Further investigation is required however, to better understand the factors or variables that control healing in these different tissues. Flexor tendon healing is a complex process. Immobilization decreases the risk of tendon rupture but help the adhesion formation. The opposite happen in early mobilization. The ideal would be to find the way to stimulate a faster tendon repair and mobilize before adhesion formation.

In conclusion, we, also, purpose this animal model for the comparative studies of different methods of suturing the tendon, to study whether how it can affect the cellular response and the development of adhesions.

\section{References}

1. Oakes BM (2003) Tissue healing and repair: tendons and ligaments, Rehabilization of sports injuries: scientific basis. Boston: Blackwell Science.

2. Murphy PG, Loitz BJ, Frank CB, Hart DA (1994) Influence of exogenous growth factors on the synthesis and secretion of collagen types I and III by explants of normal and healing rabbit ligaments. Biochem Cell Biol 72: 403-409.

3. Tillman LJ, Chasan NP (1996) Properties of dense connective tissue and wound healing, Management of common musculoskeletal disorders: physical therapy principles and methods (3rdedn) Philadelphia.

4. Hooley CJ, Cohen RE (1979) A model for the creep behavior of tendon. Int $J$ Biol Macromol 1: 123-132.

5. Abrahamsson SO (1991) Matrix metabolism and healing in the flexor tendon Experimental studies on rabbit tendon. Scand J Plast Reconstr Surg Hand Surg Suppl 23: 1-51.

6. Farkas LG, McCain WG, Sweeney P, Wilson W, Hurst LN, et al. (1973) An experimental study of the changes following silastic rod preparation of a new tendon sheath and subsequent tendon grafting. J Bone Joint Surg Am 55: 1149-1158.

7. Amiel D, Akeson WH, Harwood FL, Frank CB (1983) Stress deprivation effect on metabolic turnover of the medial collateral ligament collagen. A comparison between nine- and 12-week immobilization. Clin Orthop Relat Res: 265-270.

8. Manske PR, Lesker PA (1984) Biochemical evidence of flexor tendon participation in the repair process--an in vitro study. J Hand Surg Br 9: 117-120.

9. Gelberman RH, Manske PR, Vande Berg JS, Lesker PA, Akeson WH (1984) Flexor tendon repair in vitro: a comparative histologic study of the rabbit, chicken, dog, and monkey. J Orthop Res 2: 39-48.

10. POTENZAAD (1962) Tendon healing within the flexor digital sheath in the dog J Bone Joint Surg Am 44-44A: 49-64.

11. Garner WL, McDonald JA, Kuhn C 3rd, Weeks PM (1988) Autonomous healing of chicken flexor tendons in vitro. J Hand Surg Am 13: 697-700.

12. Manske PR, Gelberman RH, Lesker PA (1985) Flexor tendon healing. Hand Clin 1: 25-34.

13. Strickland JM (1999) Flexor tendons: acute injuries, Churchill Livigstone (4thedtn) New York.

14. Gelberman RH, Manske PR, Akeson WH, Woo SL, Lundborg G, et al. (1986) Flexor tendon repair. J Orthop Res 4: 119-128.

15. Fujita M, Hukuda S, Doida Y (1992) [Experimental study of intrinsic healing of the flexor tendon: collagen synthesis of the cultured flexor tendon cells of the canine]. Nihon Seikeigeka Gakkai Zasshi 66: 326-333. 
Citation: Sekouris N, Kefalas A, Soultanis K, Diamantopoulou K, Karagiannopoulou G, et al. (2013) Cellular Response of the Tendon Sheath in Tendon Injury: Experimental Research in New Zealand Rabbits. J Trauma Treat S4: 004. doi:10.4172/2167-1222.S4-004

Page 5 of 5

16. Ingraham JM, Hauck RM, Ehrlich HP (2003) Is the tendon embryogenesis process resurrected during tendon healing? Plast Reconstr Surg 112: 844-854.

17. Lundborg G, Rank F (1980) Experimental studies on cellular mechanisms involved in healing of animal and human flexor tendon in synovial environment. Hand 12: 3-11.

18. Russell JE, Manske PR (1990) Collagen synthesis during primate flexor tendon repair in vitro. J Orthop Res 8: 13-20.

19. Becker H, Graham MF, Cohen IK, Diegelmann RF (1981) Intrinsic tendon cell proliferation in tissue culture. J Hand Surg Am 6: 616-619.

20. Koob TJ (2002) Biomimetic approaches to tendon repair. Comp Biochem Physiol A Mol Integr Physiol 133: 1171-1192.

21. Vu TH, Werb Z (2000) Matrix metalloproteinases: effectors of development and normal physiology. Genes Dev 14: 2123-2133.

22. Evans $\mathrm{CH}$ (1999) Cytokines and the role they play in the healing of ligaments and tendons. Sports Med 28: 71-76.

23. Chang J, Most D, Thunder R, Mehrara B, Longaker MT, et al. (1998) Molecular studies in flexor tendon wound healing: the role of basic fibroblast growth factor gene expression. J Hand Surg Am 23: 1052-1058.

24. Marui T, Niyibizi C, Georgescu HI, Cao M, Kavalkovich KW, et al. (1997) Effect of growth factors on matrix synthesis by ligament fibroblasts. J Orthop Res 15 18-23.

25. Lin JH, Wang MX, Wei A, Zhu W, Diwan AD, et al. (2001) Temporal expression of nitric oxide synthase isoforms in healing Achilles tendon. J Orthop Res 19: $136-142$

26. Nakamura-Craig M, Smith TW (1989) Substance $P$ and peripheral inflammatory hyperalgesia. Pain 38: 91-98.
27. Brain SD, Williams TJ, Tippins JR, Morris HR, Maclntyre I (1985) Calcitonin gene-related peptide is a potent vasodilator. Nature 313: $54-56$

28. Harrison RK, Mudera V, Grobbelaar AO, Jones ME, McGrouther DA (2003) Synovial sheath cell migratory response to flexor tendon injury: an experimenta study in rats. J Hand Surg Am 28: 987-993.

29. McNeilly CM, Banes AJ, Benjamin M, Ralphs JR (1996) Tendon cells in vivo form a three dimensional network of cell processes linked by gap junctions. $J$ Anat 189: 593-600.

30. Jones ME, Mudera V, Brown RA, Cambrey AD, Grobbelaar AO, et al. (2003) The early surface cell response to flexor tendon injury. J Hand Surg Am 28 221-230.

31. Khan U, Edwards JC, McGrouther DA (1996) Patterns of cellular activation after tendon injury. J Hand Surg $\mathrm{Br} 21$ : 813-820.

32. Khan U, Occleston NL, Khaw PT, McGrouther DA (1998) Differences in proliferative rate and collagen lattice contraction between endotenon and synovial fibroblasts. J Hand Surg Am 23: 266-273.

33. Sharma P, Maffulli N (2005) Tendon injury and tendinopathy: healing and repair J Bone Joint Surg Am 87: 187-202.

34. Berglund M, Reno C, Hart DA, Wiig M (2006) Patterns of mRNA expression fo matrix molecules and growth factors in flexor tendon injury: differences in the regulation between tendon and tendon sheath. J Hand Surg Am 31: 1279-1287.

35. Oryan A, Moshiri A, Meimandi-Parizi AH (2012) Short and long terms healing of the experimentally transverse sectioned tendon in rabbits. Sports Med Arthrosc Rehabil Ther Technol 4: 14
This article was originally published in a special issue, Post Traumatic Stress Disorders handled by Editor(s). Dr. Agius M, University of Cambridge, UK 